Eur. J. Clin. Chem. Clin. Biochem.

Vol. 32, 1994, pp. 525-528

(C) 1994 Walter de Gruyter \& Co.

Berlin $\cdot$ New York

\title{
Phenylketonuria Screening with a Fluorometric Microplate Assay
}

\author{
By N. Lubenow, F. Diepenbrock, H. Schickling, D. Bock, R. Heckler and J. Sander \\ Staatliches Medizinaluntersuchungsamt Hannover (Public Health Laboratory Hannover), Hannover, Germany
}

(Received November 29, 1993/April 22, 1994)

Summary: A fluorometric assay in microtitre plates for the screening of phenylketonuria was evaluated and adapted to a neonatal screening programme. Using this assay, it is possible to determine quantitatively the phenylalanine concentration in dried blood spots on filter paper. The test exhibited a linear calibration curve with a good slope as well as sufficient precision and accuracy in the statistical analysis.

Interference by other amino acids and antibiotics was not observed. Only elevated concentrations of leucine interfered to a small degree.

The phenylalanine concentration in dried blood spots of 13 phenylketonuria patients correlated to that in serum. 7381 dried blood samples of newborn infants were tested simultaneously by both the fluorometric and the Guthrie test. The results did not show significant differences.

We screened 29182 newborns using the fluorometric assay and an online data processing programme. The internal repetition rate was $0.64 \%$, the external recall rate $0.15 \%$. False negative results were not observed.

In December 1991 the fluorometric method replaced the Guthrie test in our routine programme for phenylketonuria screening, and was introduced as a follow up test for phenylketonuria patients.

\section{Introduction}

Phenylketonuria is a congenital disorder of phenylalanine metabolism, which is suitable for screening. Several assays have been developed for its early detection. A fluorometric procedure for measurement of phenylalanine in serum published by McCaman \& Robins (1) has been adapted by some authors for phenylketonuria screening in dried blood spots $(2,3,4)$.

We adapted the method to our neonatal screening programme for estimation of phenylalanine in dried blood spots using a microplate $(5,6,7)$ and data processing system.

\section{Materials and Methods}

Material

Acetone (No: 14); methanol (No. 6011); ninhydrin (No. 6762) were from E. Merck, 64283 Darmstadt, Germany.
Succinic acid (No. S7501); cupric sulphate (No. C7631); sodium potassium tartrate (No. S2377); sodium carbonate (No. S4132) were from Sigma Chemicals, 82041 Deisenhofen, Germany.

$L$-Leucyl- $L$-alanine (No. 61960) was from Fluka Feinchemikalien GmbH, 89233 Neu-Ulm, Germany.

Microplates (No. 655101) were from Greiner GmbH, 72622 Nürtingen, Germany.

Fluoroplates (No. L4-411-005) and the fluorometer Fluoroscan II (No. L2 2-410-001) were from Merlin Diagnostika GmbH, 53332 Bornheim-Hersel, Germany.

\section{Solutions}

1. Solution for protein precipitation: methanol/acetone/distilled water $(3.5+3.5+1$, by vol.), stable for 2 weeks at room temperature.

2. Elution of blood spots: distilled water.

3. Succinate buffer: succinic acid $0.2 \mathrm{~mol} / \mathrm{l}$ distilled water, $\mathrm{pH} 5.9$, stable for 2 weeks at $4^{\circ} \mathrm{C}$.

4. Ninhydrin: $27 \mathrm{~g} / \mathrm{l}$ distilled water, stable for 2 weeks at $4^{\circ} \mathrm{C}$.

5. $L$-Leucyl-L-alanine: $5 \mathrm{~g} / \mathrm{l}$ distilled water, stable for 1 weeks at $4^{\circ} \mathrm{C}$. 
6. Incubation mixture: succinate buffer/ninhydrin/ $L$-leucyl- $L$-alanine $(5+3+1$, by vol.), prepared freshly.

7. Copper concentrate: $0.6 \mathrm{~g}$ cupric sulphate, $0.83 \mathrm{~g}$ sodium potassium tartrate and $17.6 \mathrm{~g}$ sodium carbonate dissolved separately in small amounts of distilled water, mixed in the described order and adjusted with distilled water to 11 , stable for 2 weeks at $4^{\circ} \mathrm{C}$.

8. Copper reagent: 2 volumes of distilled water added to 1 volume of copper concentrate, prepared freshly.

\section{Calibrators}

The heparinized blood of a healthy, fasting volunteer was supplemented with different amounts of a stock solution of phenylalanine. The final concentration was measured in the plasma by high performance liquid chromatography. Calibrators were produced as follows: $25 \mu \mathrm{l}$ of the enriched blood were dropped on filter paper cards (Schleicher \& Schüll, No. 2992, 37586 Dassel, Germany). We used phenylalanine concentrations of $0.06,0.19,0.32$ and 0.67 $\mathrm{mmol} / \mathrm{l}(1.0,3.2,5.3,11.1 \mathrm{mg} / \mathrm{dl})$ as calibrators for the assay in duplicate, and two concentrations as controls placed in the last two positions of each fluoroplate.

\section{Neonatal blood samples}

Blood of newborns was collected on filter paper cards on the fourth or fifth postnatal day and mailed to our screening laboratory, where the test was performed on the day of receipt. The blood samples were taken from our routine neonatal screening programme.

\section{Procedure}

A single disc, $4.3 \mathrm{~mm}$ in diameter, was punched out from the filter paper card of each patient and each calibrator and placed in a well of a microplate. Fourty $\mu \mathrm{l}$ of solution for protein precipitation (No. 1) were added to each well and evaporated at $60^{\circ} \mathrm{C}$ for $30 \mathrm{~min}$. The amino acids were eluted in $145 \mu$ of distilled water per well for $20 \mathrm{~min}$ on a shaker at room temperature. After removing the discs the plates were shaken again for $10 \mathrm{~min}$. An aliquot $(55 \mu \mathrm{l})$ of eluate from each well was transferred to a fluoroplate and $45 \mu \mathrm{l}$ of incubation mixture (No. 6) were added. The covered plates were incubated for $100 \mathrm{~min}$ at $60^{\circ} \mathrm{C}$ and shaken during incubation. Thereafter the plates were cooled for $5 \mathrm{~min}$ at $-20^{\circ} \mathrm{C}$ and $280 \mu \mathrm{l}$ of copper reagent (No. 8) were added. The plates were shaken again for $15 \mathrm{~min}$ and the fluorescence units were determined within $45 \mathrm{~min}$.

\section{Measurement}

A wavelength of $355 \mathrm{~nm}$ for excitation and $460 \mathrm{~nm}$ for emission was used. The fluorometer was controlled by a computer and adjusted automatically. The measured fluorescence units were transferred to the computer on-line and calculated in terms of concentrations.

\section{Evaluation}

The fluorescence units were displayed on a computer screen directly after the measurement. So it was possible to check any high values. This occurred in about $0.6 \%$ of cases, because of small dust fibres on the surfaces. After removing the fibres, the measurement was repeated without any disturbances. A data processing programme calculated the calibration curve, the coefficient of correlation $(r)$ and the phenylalanine concentrations of the blood samples. Samples with phenylalanine concentrations above the cutoff value of $0.15 \mathrm{mmol} / \mathrm{l}(2.5 \mathrm{mg} / \mathrm{dl})$ were marked and printed separately.

In cases of elevated results, the analysis was repeated on the following day. If the result exceeded the value of $0.15 \mathrm{mmol} / \mathrm{l}(2.5$ $\mathrm{mg} / \mathrm{dl}$ ) again, the responsible physician or the parents of the newborn infant were informed and a second blood sample was requested.

\section{Results \\ Linearity of the calibration curve}

Linearity was assessed by 20 replicate analyses of 10 calibrators ranging from $0.04 \mathrm{mmol} / 1(0.7 \mathrm{mg} / \mathrm{dl})$ to 1.25 $\mathrm{mmol} / \mathrm{l}(20.7 \mathrm{mg} / \mathrm{dl})$ phenylalanine with a coefficient of correlation of $r=0.995$ (fig. 1).

\section{Precision}

The coefficients of variation of the within-run precision determined by 20 replicates of 10 different calibrators containing phenylalanine concentrations between 0.04 $\mathrm{mmol} / 1(0.7 \mathrm{mg} / \mathrm{dl})$ and $1.25 \mathrm{mmol} / 1(20.7 \mathrm{mg} / \mathrm{dl}) \mathrm{did}$ not exceed $5 \%$ in the range above the cut off value of $0.15 \mathrm{mmol} / \mathrm{l}(2.5 \mathrm{mg} / \mathrm{dl})$. The coefficients of variation of the run-to-run precision were assessed by assaying 10 different calibrators on 20 consecutive days and were less than $10 \%$ with phenylalanine concentrations above the cut off value (fig. 2).

\section{Accuracy}

The fluorometric measurement of the phenylalanine concentration in dried blood spots of 13 phenylketonuria patients undergoing dietary treatment was compared with that in plasma by high performance liquid chromatography of the same blood samples. The patients showed phenylalanine concentrations in serum between $0.12 \mathrm{mmol} / 1$ (1.9 mg/dl) and $1.3 \mathrm{mmol} / \mathrm{l}(21.4 \mathrm{mg} / \mathrm{dl})$. The coefficient of correlation between both procedures was 0.979 .

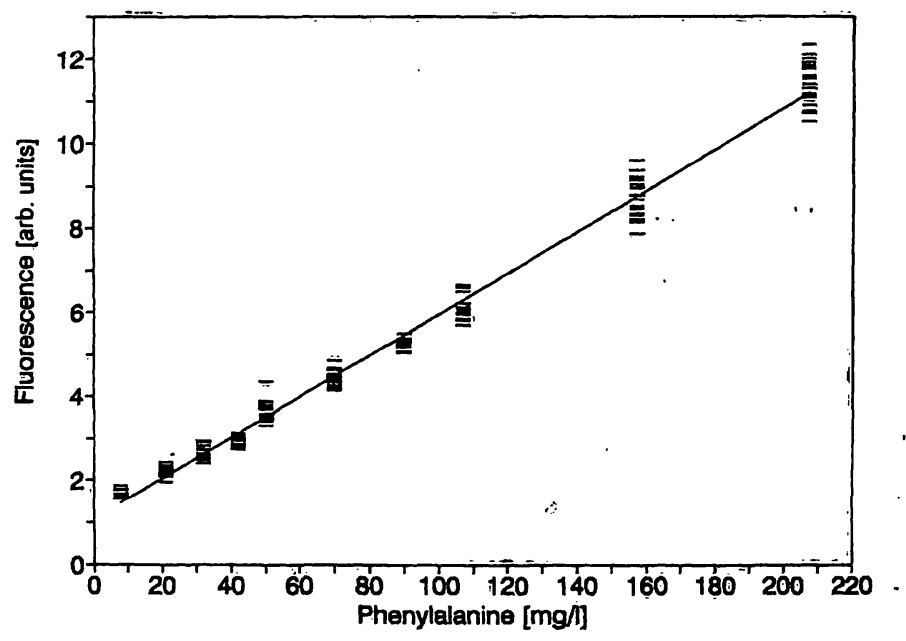

Fig. 1 Linear regression of calibration curve of 10 phenylalanine concentrations. 


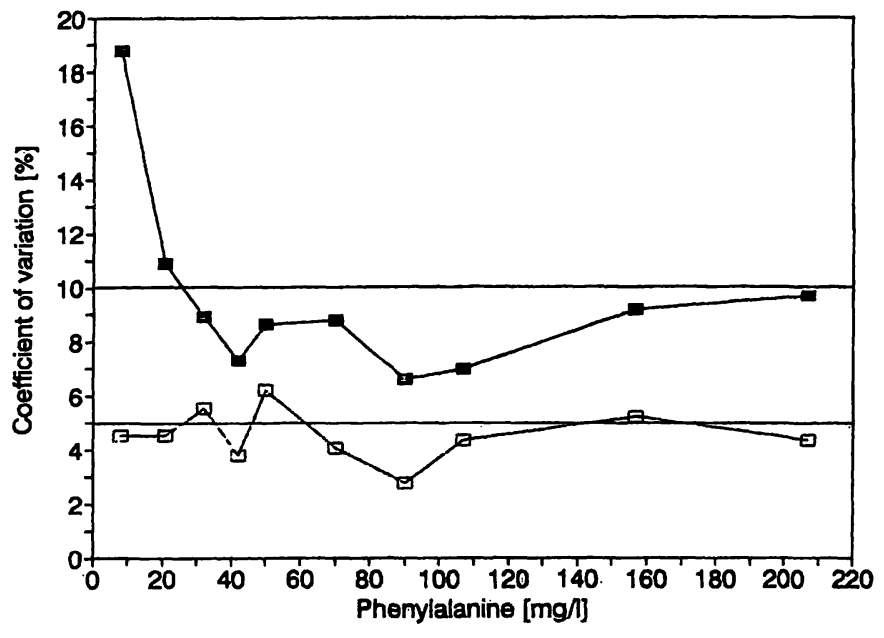

Fig. 2 Coefficients of variation of within-run precision (-口-) and run-to-run precision (- - ) of 10 phenylalanine standards.

\section{Specifity}

The influence of other amino acids was tested in dried blood spots supplemented with methionine, tyrosine, histidine, ornithine, proline, glutamine, valine, leucine and isoleucine up to $1.21 \mathrm{mmol} / \mathrm{l}(20 \mathrm{mg} / \mathrm{dl})$ instead of phenylalanine. The fluorescence of such preparations did not exceed that corresponding to a phenylalanine concentration of $0.08 \mathrm{mmol} / \mathrm{l}(1.3 \mathrm{mg} / \mathrm{dl})$, except for leucine, which caused significant interference at concentrations above $0.5 \mathrm{mmol} / 1(8 \mathrm{mg} / \mathrm{dl})$, corresponding to phenylalanine concentrations up to $0.2 \mathrm{mmol} / \mathrm{l}(3.4 \mathrm{mg} / \mathrm{dl})$.

\section{Comparison of the fluorometric and Guthrie test}

Blood samples $(\mathbf{n}=7381)$ were measured using both the fluorometric and the Guthrie test. In the Guthrie test 320 samples $(4.3 \%)$ had to be retested after heat treatment because of antibiotic substances, 51 internal repetitions $(0.7 \%)$ had to be made due to questionable results and 11 second samples $(0.15 \%)$ were requested because of elevated phenylalanine levels after repetition. The second blood samples showed normal phenylalánine concentrations.

The fluorometric assay caused only 47 internal repetitions $(0.64 \%)$, and 11 external recalls $(0.15 \%)$ were necessary. None of previous elevated phenylalanine levels could be confirmed in the second sample.

These data reveal that the low number of false positive results is a great advantage over the Guthrie test. The fluorometric test also proves to be the more suitable screening method with respect to overall processing time ( $4.5 \mathrm{~h}$ versus $24 \mathrm{~h}$ and longer), and material and reagent costs.

\section{Fluorometric routine screening}

Samples $(n=21801)$ were screened using the fluorometric method. To process 300 blood samples, one laboratory assistant needed about 4.5 hours. With a cutoff value of $0.15 \mathrm{mmol} / \mathrm{l}(2.5 \mathrm{mg} / \mathrm{dl})$ phenylalanine we had to repeat 124 of the samples $(0.57 \%)$, mostly due to unspecific fluorescence caused by dust fibres in the microwells. In 45 cases $(0.21 \%)$ the results remained positive after the repetition test, and a second sample was requested. Eight of these samples $(0.04 \%)$ had a phenylalanine concentration above the cutoff value. Those babies were introduced to a university clinic for further diagnosis. Two of them $(0.01 \%)$ were in need of treatment for hyperphenylalaninaemia. We are not aware of any false negative results.

Figure 3 shows the distribution of the blood phenylalanine concentrations of 29182 samples. The mean value is $0.06 \mathrm{mmol} / 1(1.06 \mathrm{mg} / \mathrm{dl})$ phenylalanine, $\mathrm{SD}=0.50$ $\mathrm{mg} / \mathrm{dl}$.

\section{Discussion}

The practical experience and the statistical data of this fluorometric method demonstrate its suitability for neonatal phenylketonuria screening. It also showed sufficient accuracy for dietary control of phenylketonuria patients.

The short time needed for the test allows a second analysis on the following day. Reagent costs are low and there are only few false positive results. We are not aware of false negative results. The online data processing reduces the sources of errors by laboratory staff.

In comparison with the Guthrie bacterial inhibition assay, the fluorometric method shows several important

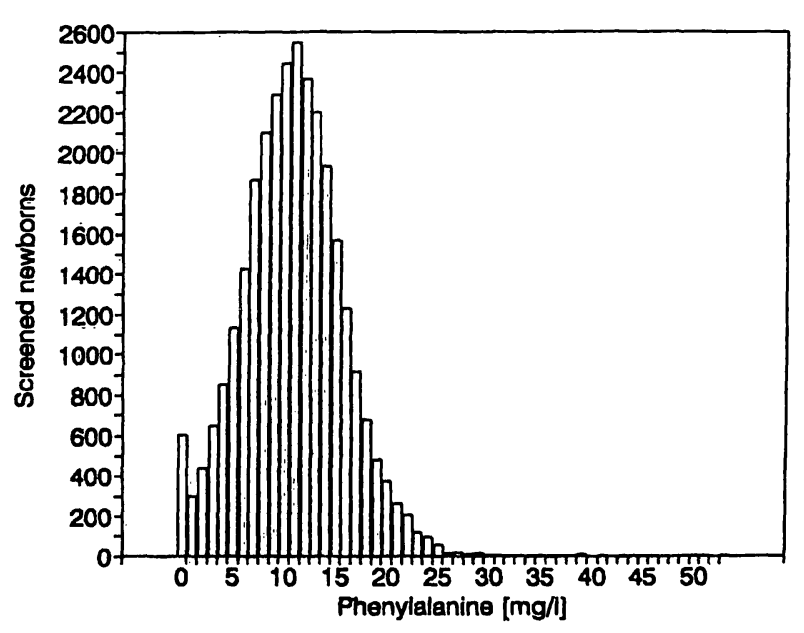

Fig. 3 Distribution of phenylalanine concentration in dried blood samples. 
advantages. Therefore the "Staatliches Medizinaluntersuchungsamt Hannover" (Public Health Laboratory of Hannover) replaced the Guthrie test for routine phenylketonuria screening in December 1991. No important problems have since been encountered in the testing of more than 100000 samples.

\section{References}

1. McCaman, M. W. \& Robins, E. (1962) Fluorometric method for determination of phenylalanine in serum. J. Lab. Clin. Med. 9, $885-890$.

2. Hill, J. B., Summer, G. K., Pender, M. W. \& Roszel, N. O. (1965) An automated procedure for blood phenylalanine. Clin. Chem. 11, 541-546.

3. Holton, J. B. (1972) A large scale comparison of the bacterial inhibition assay and the automated fluorimetric method for phenylketonuria screening. Ann. Clin. Biochem. 9, 671-680.

4. Kirkman, H. N., Carrol, C. L., Moore, E. G. \& Matheson, M. S. (1982) Fifteen year experience with screening for phenylketonuria with an automated fluorometric method. Am. J. Hum. Genet. 34, 743-752.

5. Gerasimova, N. S., Steklova, I. V. \& Tuuminen, T. (1989) Fluorometric method for phenylalanine microplate assay adapted for phenylketonuria screening. Clin. Chem. 35, 2112-2115.

\section{Acknowledgements}

We gratefully acknowledge the cooperation of Mrs. Angelika Schmidt, Mrs. Annerose Richter and Mrs. Anke Meyer from the Screening Laboratory of the Staatliches Medizinaluntersuchungsamt Hannover. We also thank Mr. Wolfgang Kohlen, Universitätsklinikum Rudolf Virchow, Berlin, for his friendly help in measuring amino acids using high performance liquid chromatography.

6. Gerasimova, N. S., Samutin, A. A., Steklova, I. V. \& Tuuminen, T. (1992) Phenylketonuria screening in Moscow using a mircroplate fluorometric method. Screening 1, 27-35.

7. Tuuminen, T. (1992) Changing of critical variables in the fluorometric microplate-based method for phenylketonuria screening. Clin. Chem. 38, 784-785.

Dr. H. Schickling

Prof. Dr. J. Sander

Staatliches Medizinaluntersuchungsamt Hannover

Roesebeckstraße 4-6

D-30449 Hannover

Germany 